\title{
Трансформация интеллектуального капитала в ценность компании в экономике знаний
}

\author{
Найденова Ю.Н. ${ }^{35}$, Осколкова М.А. ${ }^{36}$
}

Осознание значимости роста стоимости компании для всех стейкхолдеров, а также усиление роли неосязаемых активов в прочессе ее создания делают актуальным исследование механизма трансформации интеллектуального капитала в результирующие показатели. Однако сущуествующие исследования демонстрируют слабое развитие методов измерения стоимости, созданной компонентами интеллектуального капитала компании, что затрудняет анализ эффективности его использования и накладьвает ограничения на управление стоимостью компании. Настоящая работа посвящена теоретическому обзору $u$ выявлению проблемных областей для последующего анализа создания и разрушения стоимости как результата использования осязаемых и неосязаемых активов.

\section{JEL: $G 30$}

Ключевые слова: интеллектуальный капитал, создание стоимости, добавленная стоимость, структура активов, отдача от интеллектуального капитала

В конце XX века развитые финансовые рынки США повлияли на смещение акцентов в мировом финансовом менеджменте, сделали приоритетным прирост рыночной стоимости компании, а не показателей ее бухгалтерской отчетности и привели к зарождению концепции управления на основе стоимости (value-based management, VBM), рассматривающей компанию как потенциальный объект вложения денег инвесторами. Согласно данной концепции, основной целью компании является долгосрочный рост инвестиционной стоимости владельцев капитала компании. При этом нельзя ограничиваться рассмотрением интересов только собственников бизнеса, поскольку каждая компания имеет целый ряд заинтересованных сторон (стейкхолдеров), благосостояние которых необходимо максимизировать для того, чтобы обеспечивать конкурентоспособность (Cooper, 2000).

Бухгалтерские показатели деятельности компании, такие как прибыль, выручка и др., используемые в качестве измерения эффективности деятельности компании ее акционерами, не способны измерить выгоды, созданные в рамках ее функционирования для всех заинтересованных сторон. Многочисленные исследователи теории стейкхолдеров сходятся во мнении, что наилучшим показателем выгод, созданных заинтересованными сторонами компании и распространенных между ними, является добавленная стоимость (Meek, Gray, 1988; Riahi-Belkaoui, 2003; Donaldson, Preston, 1995). Добавленная стоимость представляет собой прирост благосостояния компании за счет эффективного использования ресурсов, который распределяется между акционерами, кредиторами, покупателями, работниками компании и государством (Pohlman, 2000; Stern, 2001; Riahi-Belkaoui, 2003).

В эпоху глобализации и «новой экономики» роль материальных активов отступает на второй план, поскольку они не способны создать для компании конкурентные преимущества, при этом в рамках стоимостной концепции возрастает интерес к неосязаемым активам. Влияние интеллектуального капитала и его компонентов на стоимость компании объясняет создание спреда между капитализацией и балансовой стоимостью активов компании (Lev, 1999). Кроме того, в ряде исследований экономическая добавленная стоимость (EVA, economic value added) также рассматривается в качестве суррогатного показателя интеллектуального капитала, исходя из предположения, что нормальная экономическая

\footnotetext{
${ }^{35}$ Преподаватель кафедры финансового менеджмента НИУ-ВШЭ - Пермь

${ }^{36}$ Преподаватель кафедры финансового менеджмента НИУ-ВШЭ - Пермь
} 
прибыль создается физическими и финансовыми активами, тогда как сверхприбыль нематериальными и неосязаемыми (Lev, 1999). Другим прокси-показателем, возникновение которого объясняется влиянием интеллектуального капитала, является ценность будущего роста (FGV, future growth value). Исследование Бургмана и Рууса демонстрирует, что для американских компаний доля ценности будущего роста в стоимости компании растет с каждым годом, а в ряде отраслей, характеризующихся активным использованием инновационных продуктов, превышает 100\% (Burgman, Roos, 2005). Как результат растущего осознания компаниями важности инвестирования в интеллектуальный капитал с точки зрения создания стоимости, добавленной экономической стоимости и ценности будущего роста инвестиции в интеллектуальный капитал с каждым годом возрастают, в некоторых странах превышая сумму вложений в физический и финансовый капитал (OECD, 2007; Zeghal, Maaloul, 2010). Некоторые исследователи, такие как Стюарт (Stewart, 1997) и Зихал (Zeghal, 2000) связывают подобные изменения в структуре инвестиций с переходом к экономике, основанной на знаниях, в то время как другие, такие как Эдвинссон (Edvinsson, 1997), Свейби (Sveiby, 1997) и Линн (Lynn, 1998), обосновывают рост значимости интеллектуального капитала с растущим пониманием его влияния на создание стоимости в рамках «новой экономики».

\section{1. Стоимость, добавленная интеллектуальным капиталом и его компонентами}

Если рассматривать понятие «интеллектуальный капитал» в контексте добавленной стоимости, то он представляет собой совокупность ключевых неденежных и нематериальных ресурсов, имеющих качественное и долгосрочное влияние на процесс функционирования компании (Байбурина, Головко, 2008). Таким образом, созданная компанией стоимость, выражаемая в материальной форме, сегодня во многом зависит от неосязаемых характеристик, таких, как репутация, отношения с клиентами, компетенции сотрудников и т.д. Схожее определение дают Эдвинссон и Мэлоун. В их работе интеллектуальным капиталом признаются знания, которые могут быть конвертированы в стоимость (Edvinsson, Malone, 1997). Это понятие было расширено Зихалом и Малулом (Zeghal, Maaloul, 2010), которые определяют интеллектуальный капитал как сумму всех знаний, которые могут быть использованы компанией в процессе создания компанией добавленной стоимости.

Рассмотрение добавленной стоимости в качестве одного из основных показателей результативности и эффективности использования интеллектуального капитала в последнее время все чаще становится объектом изучения в академической среде. Исследования британского Департамента промышленности и торговли показали, что успешные компании связывают способность создавать продукты и услуги с высокой добавленной стоимостью с инвестициями в интеллектуальный капитал (Zeghal, Maaloul, 2010). Некоторые исследователи считают, что задействованный капитал, состоящий из физических и финансовых активов, не является наиболее значимым для реализации стратегии компании, в отличие от интеллектуального капитала, который и позволяет компании создавать добавленную стоимость (Riahi-Belcaoui, 2003; Youndt, 2004). Связи интеллектуального капитала и созданной им добавленной стоимости посвящены работы Кимуры и др. (Kimura et al., 2010), исследовавших бразильские открытые компании, Озтюрка и Демиргунеса (Ozturk, Demirgunes, 2007), рассматривавших компании, котирующиеся на ISE (Istanbul Stock Exchange), Линна (Lynn, 2000), представившего свои результаты в статье с говорящим названием «Ключевая роль интеллектуального капитала в увеличении стоимости», а также многие другие. Недавние исследования в этой области говорят о том, что, несмотря на широкое признание добавленной стоимости ключевым показателем результативности использования нефинансовых ресурсов, сам процесс преобразования элементов интеллектуального капитала в стоимость остается дискуссионным вопросом. В качестве проблемной области это рассматривают, в частности, Диез и др., анализируя создание 
стоимости испанскими фирмами (Diez et al., 2010). Статистический анализ позволил им лишь обнаружить наличие значимой связи между элементами интеллектуального капитала и показателем добавленной стоимости. При этом остается неясным, какая часть добавленной стоимости создается инвестированным капиталом, а какая - интеллектуальными ресурсами.

Таким образом, несмотря на существование целого ряда научных работ, рассматривающих неосязаемые активы компании с точки зрения их вклада в стоимость (Pulic, 2000; Stewart, 2002; Chen, Cheng, Hwang, 2005; Tan et al., 2007; Zeghal, Maaloul, 2010; Байбурина, Головко, 2008), изучение процесса превращения интеллектуального капитала и его компонентов в финансовые результаты деятельности компании до сих пор остается перспективной областью исследования. Для решения описанного вопроса был предложен целый ряд показателей ценности, однако каждый из них не только имеет существенные недостатки с финансовой точки зрения, но и вызывает сомнения в использовании его как прокси стоимости, созданной интеллектуальным капиталом компании.

\section{2. Форма отдачи от интеллектуального капитала и его компонентов}

Помимо рассмотрения вопросов о величине отдачи от неосязаемых активов, выражаемой, в частности, добавленной стоимостью, и необходимости ее измерения (Daum, 2001; Hunter, Webster, Wyatt, 2005; Березинец, Удовиченко, Сысолятина, 2010), исследователями поднимается вопрос о том, какова форма отдачи на капитал. Поскольку ранее расходы инвестиционного типа, такие как расходы на НИОКР, маркетинговые расходы и стоимость тренингов персонала трактовались как издержки организации, а не инвестиции, не возникало потребности в измерении отдачи от них. В условиях «новой экономики» и интенсивного использования интеллектуального капитала для управления стоимостью компании необходимо не только рационально вкладывать средства в материальные активы, но также определять, являются ли инвестиции в интеллектуальный капитал компании эффективными.

Авторы более ранних работ (Arthur, 1996; Bontis, 2000; Daum, 2001) утверждают, что интеллектуальные ресурсы, в отличие от материальных, таких как земля, труд и капитал, характеризуются возрастающей отдачей на капитал. Основным аргументом в пользу такого свойства исследователи называют то, что благодаря невещественности интеллектуального капитала управление его компонентами обладает эффектом ненулевой суммы, когда вложения многократно окупаются. Даум объясняет это сетевым эффектом и экономией от масштаба за счет того, то есть первоначальные вложения в программное обеспечение или рекламу при увеличении масштаба деятельности с некоторой точки перегиба начинают приносить растущую отдачу (Daum, 2001).

C другой точки зрения, может происходить обратный процесс, когда чрезмерное инвестирование в интеллектуальный капитал разрушает стоимость. В рамках методологии расчета показателя EVA Стерн и Стюарт предлагают капитализировать расходы на научные исследования и разработки, маркетинг, рекламу и обучение персонала, для того чтобы отразить их долгосрочное влияние на стоимость компании (Stern, 2001). Таким образом, если рассматривать капитализированную величину как стоимость разработанного благодаря научно-исследовательской деятельности актива, стоимость инвестированного капитала повышается и его рентабельность снижается. В таком случае излишнее инвестирование в интеллектуальные активы, не приводящее к соответствующему повышению операционной прибыли, снижает стоимость компании.

Эмпирические исследования также не находят подтверждения возрастающей отдачи от интеллектуального капитала. Канибано провел анализ существующих на тот момент исследований и выявил, что маркетинговые расходы не имеют четкой взаимосвязи со стоимостью компании (Canibano, 2000). Хуанг и Вонг (Huang, Wang, 2008) с помощью регрессионного анализа проверили силу линейной взаимосвязи рыночной стоимости собственного капитала и прокси-показателей интеллектуального капитала, и выявили, что 
эти виды инвестиций не всегда положительно взаимосвязаны с капитализацией. В качестве таких показателей были использованы маркетинговые издержки в расчете на 1 акцию, соотношение расходов на НИОКР и чистого операционного дохода, административные издержки на 1 работника. Более того, в то время как в компаниях традиционных (индустриальных) отраслей расходы на накопление интеллектуального капитала организации положительно или нейтрально связаны с капитализацией, в высокотехнологичной электронной промышленности расходы на маркетинг имеют устойчивую отрицательную взаимосвязь со стоимостью компании. Это может свидетельствовать о том, что в традиционных отраслях инвестирование в неосязаемые интеллектуальные активы носит умеренный характер и не достигает точки насыщения, поэтому не создает значительных преимуществ, но и не приводит к разрушению стоимости. Вероятно, в отличие от традиционных, в отраслях, где интеллектуальный капитал используется более интенсивно, инвестиции в него могут превысить необходимое количество, что приведет к неэффективности и разрушению стоимости.

Ряд исследований (Shiu, 2006; Chen, Cheng, Hwang, 2005; Diez et al., 2010; Гаранина, 2009 и др.), посвященных определению вклада интеллектуального капитала в стоимость компании, также показывает схожие результаты. Обнаруживается, что для некоторых компаний характерна отрицательная отдача от интеллектуальных активов. В своем исследовании Гаранина предложила метод оценки нематериальных активов при помощи модели остаточной операционной прибыли REOI (Residual Operating Income) для определения фундаментальной ценности собственного капитала (Гаранина, 2009). В данном случае под нематериальными активами подразумевается не перечень нематериальных активов бухгалтерского баланса, а весь объем неосязаемых активов, которым владеет компания. В общем виде данная модель представляет собой капитализированную величину остаточной прибыли, рассчитанной на основе чистых активов организации, и спредом между фактической доходностью компании и среднеотраслевой.

В этом случае эффекты влияния нематериальных активов на общую доходность могут быть как положительными - в случае превышения доходности компании над среднеотраслевым уровнем, так и отрицательными - в противном случае. Таким образом, фундаментальная ценность нематериальных активов может быть даже при неотрицательном значении доходности как положительной, так и отрицательной. Результаты эмпирических исследований показали, что фундаментальная стоимость неосязаемых активов, определенная по модели Гараниной, с течением времени не только не растет, но даже падает и становится отрицательной (рис.1).

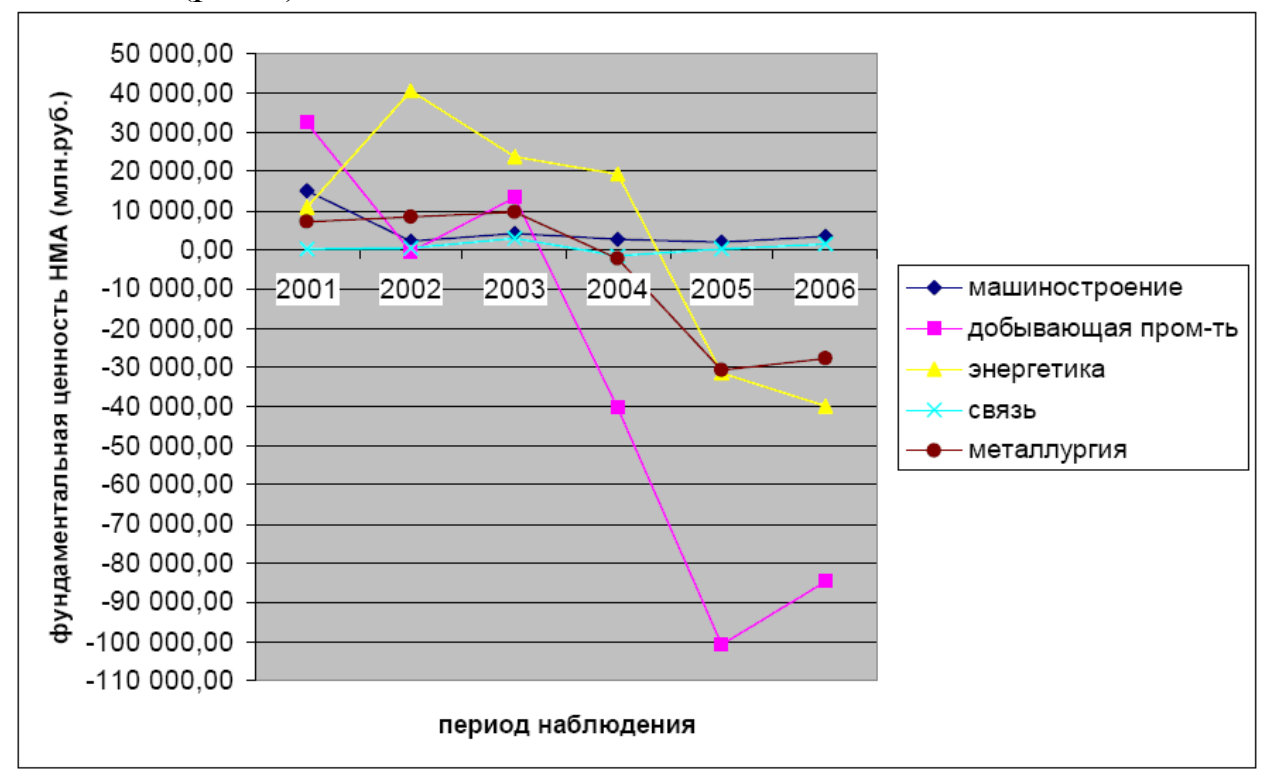

Рисунок 1. Фундаментальная стоимость нематериальных активов Источник: (Гаранина, 2009). 
Возможно, данный парадокс может быть объяснен тем, что компании имеют неоптимальную комбинацию активов и причиной отрицательного воздействия на стоимость капитала является несбалансированность между количеством материальных и неосязаемых активов компании и/или дисбаланса между компонентами интеллектуального капитала.

Если считать интеллектуальный капитал частью портфеля активов компании, то, вероятно, существует оптимальная структура активов, позволяющая создавать наибольшую стоимость. Как предполагают некоторые исследователи, стоимость интеллектуального капитала подчиняется правилу мультипликации, то есть существует некая синергия между его компонентами. Предполагая некую комплементарность интеллектуальных активов, можно предположить, что недоинвестирование в один из компонентов также ведет к значительному недоиспользованию потенциала роста стоимости компании. И наоборот, излишек инвестирования приведет к высоким затратам при отсутствии роста отдачи. Таким образом, возможно существование предела насыщения компонентами интеллектуального капитала, превышение которого ведет к разрушению стоимости компании.

Хуанг и Лью (Huang, Liu, 2005) выявили, что взаимосвязь инновационного капитала, в частности НИОКР, с эффективностью работы компании является нелинейной и предположительно U-образной. Если это действительно так, то отдача от интеллектуального капитала, по крайней мере некоторых его компонентов, может подчиняться закону возрастающей отдачи до некоторой точки перегиба, а затем - закону убывающей отдачи. Следовательно, возможна ситуация, когда инвестирование в интеллектуальные активы даст отрицательную отдачу, станет неэффективным и не приведет к росту стоимости компании.

Таким образом, обзор существующих исследований демонстрирует слабое развитие методов измерения добавленной стоимости и добавленной экономической стоимости, созданных интеллектуальным капиталом компании и его компонентами, что затрудняет анализ эффективности использования интеллектуального капитала и накладывает ограничения на управление стоимостью компании. Кроме того, дискуссионным остается вопрос о форме отдачи от интеллектуального капитала и значимости структуры активов, в том числе неосязаемых, с точки зрения создания стоимости, поскольку теоретические предположения расходятся с результатами эмпирических исследований.

\section{3. Выдвижение гипотез}

Область исследований, посвященных оценке ценности, созданной интеллектуальным капиталом и его компонентами, а также влиянию его структуры на эффективность деятельности компании, является актуальной ввиду отсутствия единства мнений авторов теоретических работ и малого количества существующих эмпирических исследований. На основе проведенного выше обзора можно предположить следующие особенности механизма трансформации интеллектуального капитала в стоимость:

1. Прокси-показатели интеллектуального капитала и его компонентов способны отразить создание и разрушение стоимости. Прокси-показатели планируется выбирать на основе анализа существующих теоретических и эмпирических исследований, а затем проверить объясняющую способность каждого из них, без учета их взаимовлияния.

2. Прокси-показатели интеллектуального капитала и его компонентов взаимно влияют друг на друга в процессе создания и разрушения стоимости. Предполагаемая многими исследователями, в частности Пуликом в модели VAIC, аддитивность добавленной стоимости, созданной всем интеллектуальным капиталом, также может не выполняться на практике и требует более глубокого анализа. Предположительно некоторые компоненты могут усиливать влияние друг друга на добавленную стоимость, в то время как другие - наоборот, ослаблять.

3. Прокси-показатели компонентов интеллектуального капитала нелинейно связаны с его ценностью. В научной среде распространено мнение о том, что для 
интеллектуального капитала работает правило мультипликативности, которое подразумевает, что его стоимость может быть определена как произведение стоимостей его компонентов, что предполагается проверить в рамках выдвинутой гипотезы.

4. Структура материальных и интеллектуальных активов влияет на стоимость компании. По аналогии с микроэкономическим представлением об оптимальном соотношении труда и капитала в компании, можно сделать предположение о наличии оптимального соотношения между материальными и интеллектуальными активами.

\section{Заключение}

Таким образом, анализ теоретических и эмпирических работ по тематике интеллектуального капитала и его взаимосвязи со стоимостью компании позволил выделить потенциальную область исследования - механизм трансформации интеллектуального капитала и его компонентов в стоимость компании. В рамках данного направления может быть выделено два блока задач: определение показателей, характеризующих величину и отдачу от каждого из компонентов интеллектуального капитала компании, которые могут быть формализованы, измерены и исследованы. Другой блок представляет собой более глубокое исследование самого механизма трансформации, а именно свойства взаимного влияния компонентов интеллектуального капитала и их связь со структурой материальных и финансовых активов.

\section{Список литературы}

1. Arthur, B. (1996), Increasing returns and the new world of business, Harvard Business Review, July-Aug., (1996) 1-10.

2. Bontis, N. (2000), Assessing Knowledge Assets: A review of the models used to measure intellectual capital, In J. McKeen (Ed.), Knowledge-Based Enterprises, Kingston, Canada: Queen's Management Research Centre for KBE, republished from International Journal of Management Reviews (2000) 1-24.

3. Cañibano, L., García-Ayuso, M., and Sánchez, P. (2000), Accounting for Intangibles: A Literature Review, Journal of Accounting Literature, 19 (2000) 102-130.

4. Chen, M., Cheng, S., and Hwang, Y. (2005), An Empirical Investigation of the Relationship Between Intellectual Capital and Firms' Market Value and Financial Performance, Journal of Intellectual Capital, 6(2) (2005) 159-176.

5. Cooper, S. (2000), Shareholder Wealth Maximisation: A Stakeholder Perspective, G. Arnold \& M. Davies (eds), Value Based Management, London: Wileys. P. 81-104.

6. Daum, J.H. (2001), Value Drivers Intangible Assets - Do We Need A New Approach to Financial and Management Accounting. A Blueprint for an Improved Management System. P. 22.

7. Di'ez, J. M., Ochoa, M. L., Prieto, M.B., Santidria'n, A. (2010), Intellectual capital and value creation in Spanish firms, Journal of Intellectual Capital, 11(3) (2010) 348-367.

8. Donaldson, T., Preston, L.E. (1995), The stakeholder theory of the corporation: concepts, evidence and implications, Academy of Management Review, 20(1) (1995) 65-91.

9. Edvinsson, L. (1997), Developing intellectual capital at Scandia, Long Range Planning, 30(3) (1997).

10. Edvinsson, L., Malone, M. (1997), Intellectual Capital: Realising Your Company's True Value by Finding its Hidden Brainpower: Harper Collins, New York.

11. Huang, C., Liu, J. (2005), Exploration for the Relationship Between Innovation, IT and Performance, Journal of Intellectual Capital, 6(2) (2005) 237-252.

12. Hunter, L.C., Webster, E. and Wyatt, A. (2005), Measuring Intangible Investment, Melbourne Institute Working Paper. Ser. 15/05, Melbourne Institute of Applied Economic 
and Social Research, Australia, 2005.

13. Kimura, H., Cruz Basso, L.F., Nogueira, S.G., de Barros, L.J. (2010), The impact of intellectual capital on value added of Brazilian companies traded at the BMF-Bovespa, Journal of International Finance \& Economics, (2010).

14. Lev, B. (1999), R\&D and Capital Markets, Journal of Applied Corporate Finance, (1999) 21-35.

15. Lynn, B. (1998), Intellectual Capital, CMA Magazine,72(1) (1998) 10-15.

16. Lynn, B. (2000), Intellectual Capital Key to Value Added Success, Chartered Accountants Journal, 79(3) (2000) 24-32.

17. Meek, G.K., Sidney J.G. (1998), The Value added statement: An innovation for the U.S. companies, Accounting Horizons, (1998) 73-81.

18. Mertins, K., Heisig, P.,Vorbeck, J. (2003), Knowledge management: concepts and best practices, second edition, Springer-Verlag. P. 156-157.

19. OECD (2007), Policy brief: creating value from intellectual assets, OECD Observer, Paris.

20. Ozturk, M. B.; Demirgunes, K. (2007), Determination of Effect of Intellectual Capital on Firm Value via Value Added Intellectual Coefficient Methodology: An Empirical Study on ISE-Listed Manufacturing Firms, ISE Review, 10(37) (2007) 59-77.

21. Pohlman, R.A., Gardiner, G.S. (2000), Value Driven Management: How to Create and Maximize Value over Time for Organizational Success: Pohlman, Inc., New York. P. 240.

22. Riahi-Belkaoui A. (2003), Intellectual capital and firm performance of US multinational firms, Journal of Intellectual capital, 4(2) (2003).

23. Shiu, H.-J. (2006), The Application of the Value Added Intellectual Coefficient to Measure Corporate Performance: Evidence from Technological Firms, International Journal of Management, 23(2) (2006) 356-365.

24. Stewart, T.A. (1997), Intellectual Capital: The new Wealh of organization: Nicholas Brealey, London.

25. Stewart, T.A. (2002), The case against knowledge management, Business 2.0, 3(2) (2002).

26. Sveiby, K. (1997), The New Organisational Wealth: Managing and Measuring Knowledge Based Assets: Berrett-Koehler, San Francisco, CA.

27. Tan, H.P., Plowman, D., Hancock, P. (2007), Intellectual capital and financial returns of companies, Journal of Intellectual capital, 8(2) (2007).

28. Youndt, M., Subramaniam, M., Snell, S. (2004), Intellectual capital profiles: An examination of investments and returns, Journal of Management Studies, 41 (2) (2004) $335-362$.

29. Zeghal, D. (2000), New assets for the new economy, FMI Journal, 11 (2) (2000).

30. Байбурина Э.Р., Головко Т.В. Эмпирическое исследование интеллектуальной стоимости крупных российских компаний и факторов ее роста // Корпоративные финансы. 2008. № 6.

31. Березинец И.В., Сысолятина Е.В. Удовиченко О.М. Оценка вклада интеллектуального капитала в создание ценности компании// Корпоративные финансы. 2010. № 3 (15). C. 5-22.

32. Гаранина Т.А. Роль нематериальных активов в создании ценности компании: теоретические и практические аспекты // Корпоративные финансы. 2009. № 4 (12).С. 79-96. 